\title{
Sex-specific responses to mineralocorticoid receptor antagonism in hypertensive African American males and females
}

\author{
John S. Clemmer ${ }^{1 *}\left(\mathbb{D}\right.$, Jessica L. Faulkner ${ }^{4}$, Alex J. Mullen ${ }^{1}$, Kenneth R. Butler ${ }^{3}$ and Robert L. Hester ${ }^{1,2}$
}

\begin{abstract}
Background: African Americans (AA) develop hypertension (HTN) at an earlier age, have a greater frequency and severity of HTN, and greater prevalence of uncontrolled HTN as compared to the white population. Mineralocorticoid antagonists have been shown to be very effective in treating uncontrolled HTN in both AA and white patients, but sexspecific responses are unclear.

Methods: We evaluated the sex-specific impact of mineralocorticoid antagonism in an AA population. An AA cohort ( $n=1483$ ) from the Genetic Epidemiology Network of Arteriopathy study was stratified based on sex and whether they were taking spironolactone, a mineralocorticoid antagonist, in their antihypertensive regimen.

Results: As compared to AA women not prescribed a mineralocorticoid antagonist, AA women taking spironolactone $(n=9)$ had lower systolic and diastolic blood pressure despite having a similar number of antihypertensive medications. The proportion of AA women with uncontrolled HTN was significantly less for patients taking spironolactone than for patients not prescribed spironolactone. Interestingly, none of these associations were found in the AA males or in white females.

Conclusions: Our data suggests that spironolactone is particularly effective in reducing blood pressure and controlling HTN in AA women. Further research into the impact of this therapy in this underserved and understudied minority is warranted.
\end{abstract}

Keywords: Sex-specific, Hypertension, Mineralocorticoid antagonist, African American

\section{Introduction}

Roughly one in three American adults is hypertensive [1]. Hypertension (HTN) is the most significant predictor of coronary events, stroke, and cardiovascularrelated mortality [2, 3]. General fist-line treatment therapies for HTN include angiotensin II type I receptor blockers (ARBs), angiotensin-converting enzyme (ACE) inhibitors, calcium channel blockers, adrenergic blockers, and thiazide diuretics. Despite the noted efficacy of these treatments [4-6], uncontrolled HTN remains prevalent, affecting $\sim 30 \%$ of hypertensive adults [7].

\footnotetext{
* Correspondence: jclemmer@umc.edu

${ }^{1}$ Department of Physiology and Biophysics, Center for Computational Medicine, University of Mississippi Medical Center, 2500 North State Street, Jackson, MS 39216-4505, USA

Full list of author information is available at the end of the article
}

African Americans (AA) develop HTN earlier and have a lower rate of controlled HTN than other ethnicities [1, 8-12]. AA characteristically develop HTN without an increase in renin-angiotensin system activity, which corresponds to a decreased efficacy of ARBs and ACE inhibitors in this ethnic group as compared to Caucasians [13-16]. Although AA typically have low-renin HTN, the ratio of circulating aldosterone:renin is elevated during HTN $[17,18]$. Importantly, an elevated aldosterone:renin ratio is emerging as a prognostic tool for clinical measurement of salt-sensitive HTN, a phenotype that is particularly common in AA [19-21]. Furthermore, aldosterone levels correlate with blood pressure (BP) and vascular function in AA patients [22]. Much of the work on blocking aldosterone's effects through mineralocorticoid receptor antagonism

(c) The Author(s). 2019 Open Access This article is distributed under the terms of the Creative Commons Attribution 4.0 International License (http://creativecommons.org/licenses/by/4.0/), which permits unrestricted use, distribution, and 
to treat HTN has been done in populations that were predominantly white males [23, 24].

AA women are more likely to develop salt-sensitive HTN as compared to both AA men and white women, a manifestation characterized by an elevated aldosterone:renin ratio [19-21, 25]. In addition, in a predominantly AA population, obese women have a greater BP lowering response to mineralocorticoid receptor antagonists [26]. Experimental data, from obese mouse models, suggests that mineralocorticoid receptor antagonists ameliorate obesity-associated vascular dysfunction, diastolic dysfunction, and HTN in female, but not male mice [27-29]. Therefore, in the current study, we hypothesized that spironolactone, a mineralocorticoid receptor antagonist, has sex-specific efficacy in a cohort of AA patients. An additional analysis was done on white females to assess race specificity.

\section{Methods}

\section{Study population}

The Genetic Epidemiology Network of Arteriopathy (GENOA) study is one of four networks in the Family Blood Pressure Program investigating cardiac and renal complications of HTN in whites and AA [30]. This study was designed to be a multicenter community-based study to identify genes influencing $\mathrm{BP}$ and the development of target organ damage due to HTN. The AA participants were recruited from Jackson in Hinds County, Mississippi, while the non-Hispanic white participants were recruited from Rochester in Olmsted County, Minnesota. From 1996 to 2000 (phase I), sibships with at least 2 individuals diagnosed with essential HTN prior to the age of 60 years were enrolled in Jackson (AA subjects, $n=1854$ ) and Rochester (white subjects, $n=1583$ ). From 2001 to 2004 (phase II), these participants returned for a second study visit and underwent a physical examination, provided blood samples and underwent characterization of subclinical markers of arteriosclerosis. All data presented in the current study are from phase II. The GENOA study was approved by the Institutional Review Board at both institutions (University of Mississippi Medical Center and Mayo Clinic), and all participants gave written informed consent.

Blood samples were collected into Vacutainers with ethylenediaminetetraacetic acid (Becton Dickinson, Franklin Lakes, NJ, USA) for determining plasma glucose and creatinine in the Mayo General Clinical Research Center Immunochemical Core Laboratory. The Mayo Clinic Quadratic equation was used to estimate glomerular filtration rate (eGFR) using plasma creatinine. Standardized echocardiography was performed by trained field-center technicians at New York Presbyterian Hospital-Weill Cornell Medical Center.

\section{Measurements of covariates}

Demographics and medical history were collected from standard questionnaires. Height was taken from a stadiometer, and weight was measured by electronic balance to calculate body mass index (BMI). Resting systolic and diastolic blood pressure (SBP and DBP, respectively) were measured by an automated BP monitor (Dinamap, Critikon Corporation, Tampa, FL, USA). BP was averaged from three measurements that were taken from the right arm after being seated for at least $5 \mathrm{~min}$.

Classification of HTN was based on a definitive clinical diagnosis by a physician based on SBP $\geq 140$ or $\mathrm{DBP} \geq 90 \mathrm{mmHg}$. The proportion of individuals with uncontrolled HTN was defined as individuals with HTN not being controlled ( $\mathrm{SBP} \geq 140$ or $\mathrm{DBP} \geq 90 \mathrm{mmHg}$ ). Diabetes classification was based on fasting serum glucose $\geq 126 \mathrm{mg} / \mathrm{dL}$ or existing oral hypoglycemic medication. BP medication use and previous medical history such as stroke or coronary heart disease (CHD) were obtained from questionnaires completed by the participants. CHD was defined as previous myocardial infarction (MI), coronary artery bypass surgery, or angioplasty [31]. Mineralocorticoid receptor antagonist use was indicated by patient medicine regimens that included oral prescriptions of spironolactone or eplerenone. Dosage and frequency were not reported.

\section{Statistical analysis}

A total of 2759 participants (1518 from Jackson, MS, USA, and 1241 from Rochester, MN, USA) completed both GENOA visits. Of the 1482 AA individuals with echocardiography data, there were 1446 AA patients screened with definitive normotensive/HTN diagnoses and 1406 of these individuals had no evidence of heart failure (ejection fraction $>40$ ). None of the white participants had echocardiography data. Because only 3 white males were taking a mineralocorticoid antagonist, this group was excluded from this study. Direct statistical comparisons between AA and white groups were not performed. There were 684 white female individuals with definitive normotensive/HTN diagnoses who were included in the analysis. Data were summarized using proportions for categorical variables and means (standard deviations) for quantitative variables. Chi-squared tests were used for comparison across categories (prevalence \%). Non-dichotomous data were analyzed with ANOVA for normally distributed variables. When assumptions of normality were not justified, the data were also analyzed with the nonparametric Mann-Whitney test, as appropriate. All statistical analyses were performed using GraphPad Prism 5 (La Jolla, CA, USA). Probability was based on two-tailed tests of significance, and significance was considered $P<0.05$. 


\section{Results}

AA patients were classified into 6 groups: male normotensive patients (AA MN, $n=92$ ), male HTN patients not taking spironolactone (AA MH, $n=301$ ), male HTN patients taking spironolactone (AA $\mathrm{MH}+\mathrm{S}, n=9)$, female normotensive patients (AA FN, $n=172$ ), female HTN patients not taking spironolactone (AA FH, $n=823$ ), and female HTN patients taking spironolactone $(\mathrm{AA} \mathrm{FH}+\mathrm{S}$, $n=9$ ). For additional comparisons, there were $n=684$ white female patients; of which, $n=182$ were normotensive (white FN), $n=490$ with HTN (white FH), and $n=12$ individuals with HTN who were also treated with spironolactone (white $\mathrm{FH}+\mathrm{S}$ ). Note that each patient's data was collected at a single time point. No follow-up measurements were reported.

\section{HTN with or without spironolactone in AA patients}

Patients classified as hypertensive had significantly greater BP than did all normotensive counterparts (Fig. 1, Table 2). Figure 1 demonstrates the SBP and DBP for the $6 \mathrm{AA}$ groups. AA $\mathrm{MH}+\mathrm{S}$ patients showed no significant $\mathrm{SBP}$ or DBP differences compared with AA MH patients (SBP $134 \pm 26$ vs. $139 \pm 22 \mathrm{mmHg}$; $\mathrm{DBP} 73 \pm 8$ vs. $78 \pm 11$ $\mathrm{mmHg}$ ). However, AA $\mathrm{FH}+\mathrm{S}$ patients showed significantly lower SBP $(122 \pm 26$ vs. $139 \pm 22)$ and DBP $(66 \pm 6$ vs. $73 \pm 10$ ) as compared with AA FH patients.

Baseline demographics, laboratory data, and prevalence of comorbid conditions are shown in Table 1. AA patients had a BMI of $32 \pm 7 \mathrm{~kg} / \mathrm{m}^{2}$ with an age of $63 \pm 9$ years. In AA females, compared with HTN, those taking spironolactone did not have significantly different age, BMI, number of antihypertensive medications, eGFR, or left ventricular (LV) mass. However, as compared to AA FH, $\mathrm{FH}+\mathrm{S}$ patients did have significantly higher HTN duration, lower total urinary protein, and a significantly less proportion with uncontrolled HTN (Table 1). Additionally, AA FH $+\mathrm{S}$ had a statistically similar prevalence of CHD (11\% vs. $9 \%)$ and myocardial infarction $(11 \%$ vs. $4 \%$, $p=0.3)$ as compared to AA FH. As compared to their female counterpart, AA MH patients showed significantly greater prevalence of $\mathrm{CHD}, \mathrm{MI}$, and stroke (Table 1). In AA, HTN groups also had significant increases in LV mass (Table 1). In AA FH $+\mathrm{S}$, there were similar stroke volume ( $79 \pm 14$ vs. $77 \pm 14, p=0.7)$, ejection fraction $(60 \pm 5$ vs. $62 \pm 6, p=0.1$ ), and cardiac output (5237 \pm 681 vs. $5195 \pm$ $1190, p=0.6$ ) as compared to AA FH (not shown). In the entire cohort, HTN was associated with a significantly higher prevalence of CHD, MI, stroke, diabetes, increased age, greater BMI, and lower eGFR (Tables 1 and 2).

\section{Normotensive vs. HTN and male vs. female}

In both male and female AA, HTN groups had significantly increased total urinary protein as compared to normotension (Table 1); however, this difference was not
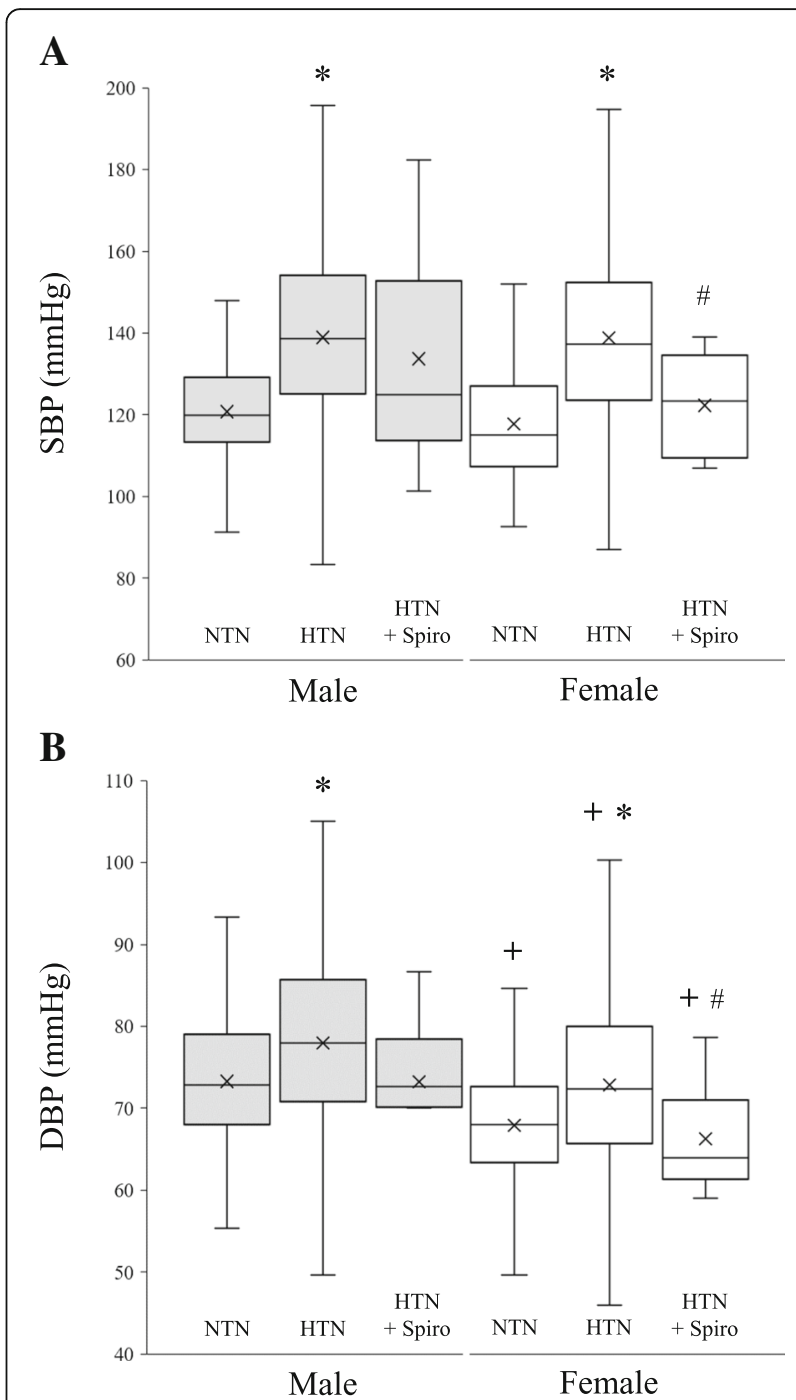

Fig. 1 Systolic and diastolic pressures from African American males (dark) and females (light) with normal blood pressure (NTN), hypertension (HTN), or hypertension with spironolactone included in their antihypertensive regimen (HTN + Spiro) shown as box-whisker plots. ${ }^{*} p<0.05$ vs. NTN, $\# p<0.05$ vs. HTN, $+p<0.05$ vs. male

significant in white females (Table 2). As compared to AA female counterparts, AA males consistently had greater LV mass (Table 1), end diastolic volume, and cardiac output (not shown). In AA HTN groups, males also consistently had a greater prevalence of CHD, MI, and stroke as compared to females (Table 1).

\section{HTN with or without spironolactone in white female patients}

Baseline demographic and laboratory data for white females are shown in Table 2. White females did not have echocardiographic data. As compared to white $\mathrm{FH}$ patients, white $\mathrm{FH}+\mathrm{S}$ patients did not have significantly different age, BMI, eGFR, duration of HTN, or number 
Table 1 Characteristics and prevalence of comorbid conditions in African American males and females

\begin{tabular}{|c|c|c|c|c|c|c|}
\hline \multirow[t]{2}{*}{ Variable } & \multicolumn{3}{|l|}{ Men $(n=402)$} & \multicolumn{3}{|c|}{ Women $(n=1004)$} \\
\hline & NTN $(n=92)$ & $\operatorname{HTN}(n=301)$ & HTN + Spiro $(n=9)$ & NTN $(n=172)$ & $\operatorname{HTN}(n=823)$ & HTN + Spiro $(n=9)$ \\
\hline Age (year) & $58 \pm 9$ & $65 \pm 9^{*}$ & $63 \pm 9$ & $56 \pm 10$ & $64 \pm 9^{*}$ & $68 \pm 9^{*}$ \\
\hline BMI $\left(\mathrm{kg} / \mathrm{m}^{2}\right)$ & $28 \pm 5$ & $29 \pm 5^{*}$ & $34 \pm 6^{* \#}$ & $31 \pm 7^{+}$ & $33 \pm 7^{*+}$ & $33 \pm 4$ \\
\hline HTN medications & 0 & $1.7 \pm 1.1^{*}$ & $2.7 \pm 1.3^{* \#}$ & 0 & $1.7 \pm 1.1^{*}$ & $1.8 \pm 0.8^{*}$ \\
\hline HTN duration (year) & 0 & $15 \pm 12^{*}$ & $15 \pm 11^{*}$ & 0 & $17 \pm 13^{*}$ & $29 \pm 11^{* \#+}$ \\
\hline eGFR (ml/min) & $104 \pm 17$ & $87 \pm 24^{*}$ & $93 \pm 14^{*}$ & $96 \pm 10^{+}$ & $87 \pm 14^{*}$ & $79 \pm 16^{*}$ \\
\hline LV mass $\left(\mathrm{g} / \mathrm{m}^{2}\right)$ & $75 \pm 14$ & $90 \pm 22^{*}$ & $90 \pm 7^{*}$ & $68 \pm 12^{+}$ & $80 \pm 18^{*^{+}}$ & $73 \pm 10+$ \\
\hline Total urinary protein (mg) & $4 \pm 7$ & $16 \pm 44^{*}$ & $11 \pm 10^{*}$ & $4 \pm 6$ & $12 \pm 34^{*}$ & $3 \pm 3^{\#+}$ \\
\hline Uncontrolled HTN (\%) & 0 & $48^{*}$ & $44^{*}$ & 0 & $46^{*}$ & $0^{\#+}$ \\
\hline CHD (\%) & 2 & $17^{*}$ & $22^{*}$ & 1 & $9^{*+}$ & $11^{*}$ \\
\hline MI (\%) & 0 & $10^{*}$ & $22^{*}$ & 1 & $4^{*+}$ & $11^{*}$ \\
\hline Stroke (\%) & 1 & $10^{*}$ & $22^{*}$ & 1 & $5^{*+}$ & 0 \\
\hline Diabetes (\%) & 10 & $30^{*}$ & 11 & 8 & $31^{*}$ & $33^{*}$ \\
\hline
\end{tabular}

NTN indicates normotension, HTN hypertension, HTN + Spiro hypertension with spironolactone treatment, BMI body mass index, HTN hypertension, eGFR estimate glomerular filtration rate, $L V$ left ventricle, $C H D$ coronary heart disease, $M I$ myocardial infarction. ${ }^{*} p<0.05$ vs. NTN, $\# p<0.05$ vs. HTN, $+p<0.05$ vs. men

of HTN medications (Table 2). Unlike AA females, white $\mathrm{FH}+\mathrm{S}$ patients showed no significant differences in SBP (132 \pm 24 vs. $136 \pm 20, p=0.6), \mathrm{DBP}(70 \pm 12$ vs. $73 \pm 10$, $p=0.5$ ), or prevalence of uncontrolled HTN (25\% vs. $42 \%, p=0.2$ ) compared with white FH patients that were not on spironolactone. $\mathrm{FH}+\mathrm{S}$ patients did have a significantly higher incidence of diabetes as compared to $\mathrm{FH}$ individuals (Table 2).

\section{Discussion}

The major findings of this study were that in older hypertensive patients, (1) AA women treated with spironolactone were better controlled than AA women who were on different antihypertensive regimens, and (2) while AA females received benefit from spironolactone, spironolactone treatment appeared to have no BP-lowering effect in AA men or white females.

As compared to AA $\mathrm{MH}$, AA $\mathrm{MH}+\mathrm{S}$ used significantly more antihypertensive medications on average but had no significant difference in SBP and had a statistically similar proportion of uncontrolled HTN (Table 1). $\mathrm{FH}+\mathrm{S}$ patients were taking a similar number of medications as FH patients but still had significantly better BP control ( $16 \mathrm{mmHg}$ lower) and lower incidence of uncontrolled HTN (Fig. 1, Table 1). White females on spironolactone (white $\mathrm{FH}+\mathrm{S}$ ) appeared to have no benefit as compared to white FH (Table 2). This data suggests a sex-specific benefit, particularly in AA, from this

Table 2 Characteristics and prevalence of comorbid conditions in white females

\begin{tabular}{llll}
\hline Variable & NTN $(n=182)$ & HTN $(n=490)$ & HTN + Spiro $(n=12)$ \\
\hline Age (year) & $51 \pm 9$ & $61 \pm 9^{*}$ & $58 \pm 11^{*}$ \\
BMI (kg/m $\left.{ }^{2}\right)$ & $29 \pm 7$ & $32 \pm 7^{*}$ & $34 \pm 5^{*}$ \\
SBP (mmHg) & $120 \pm 13$ & $136 \pm 20^{*}$ & $132 \pm 24^{*}$ \\
HTN medications & 0 & $1.6 \pm 0.9^{*}$ & $1.7 \pm 0.8^{*}$ \\
HTN duration (year) & 0 & $14 \pm 12^{*}$ & $22 \pm 14^{*}$ \\
eGFR (ml/min) & $100 \pm 8$ & $90 \pm 13^{*}$ & $90 \pm 11^{*}$ \\
Total urinary protein (mg) & $2 \pm 2$ & $2 \pm 4$ & $2 \pm 1$ \\
Uncontrolled HTN (\%) & 0 & $42^{*}$ & $25^{*}$ \\
CHD (\%) & 1 & $11^{*}$ & $25^{*}$ \\
MI (\%) & 0 & $5^{*}$ & 0 \\
Stroke (\%) & 1 & $3^{*}$ & $8^{*}$ \\
Diabetes (\%) & 3 & $13^{*}$ & $42^{* \#}$
\end{tabular}

NTN normotension, HTN hypertension, HTN + Spiro hypertension with spironolactone treatment, BMI body mass index, HTN hypertension, eGFR estimate glomerular filtration rate, $L V$ left ventricle, CHD coronary heart disease, MI myocardial infarction. ${ }^{*} p<0.05$ vs. NTN, \#p<0.05 vs. HTN 
antihypertensive therapy and could help further patientspecific medicine in this group of older ( 65 years) hypertensive women.

While there were no significant BP associations in AA males or white females with spironolactone use, this may have been due to small sample sizes. Mineralocorticoid receptor antagonists have been well characterized and shown to be superior in BP control as compared to other drugs in both white and black populations [11, 32-34]. Spironolactone has greater efficacy in patients with higher sodium diets [35] or with lower renin levels [11, 36] and lowers BP in white populations, regardless of age or gender [37]. In a cohort of white patients with HTN, spironolactone lowered SBP $\sim 4 \mathrm{mmHg}$ more than other antihypertensive drugs [36]. Comparatively, a lower SBP (4-6 $\mathrm{mmHg}$ ) was also found in both AA males and white females in the current study (Fig. 1, Table 2), although not reaching statistical significance. Spironolactone has also been shown to have significant BP-lowering effects in the black population [11,33]. Recently, in diabetic African patients (mostly female) with resistant HTN and renal disease, spironolactone significantly reduced SBP $(\sim 30$ $\mathrm{mmHg}$ ), but sex differences were not reported [33].

Specific race and sex differences in the response to mineralocorticoid antagonists have not been well characterized. Comparing AA with whites, most clinical studies have found statistically similar reductions in BP with spironolactone [11, 34, 38]. However, in a population of mostly hypertensive AA, females tended to have a $\sim 6$ $\mathrm{mmHg}$ greater fall in SBP in response to spironolactone as compared to males, but this did not reach significance [11]. These data are similar to another study demonstrating obese females have a greater BP reduction with mineralocorticoid antagonism as compared to men, in a primarily type 2 diabetic, AA population [26]. Our data showing AA $\mathrm{FH}+\mathrm{S}$ have significantly lower BP as compared to AA females on a different antihypertensive regimen (AA FH) support these findings and warrant further investigation. These data suggest that spironolactone treatment may be more efficacious in certain populations, including female AA and patients with high-sodium intake and low-renin levels.

It is important to note that the clinical population observed in the current study is a predominantly obese population. Obesity is a significant contributor to HTN and is believed to be an underlying risk factor in most hypertensive patients [39-43]. While both obese men and women are more likely to develop HTN and cardiovascular diseases, emerging experimental and clinical data suggests that the contribution of obesity to HTN is sex-specific [44]. In particular, the contribution of obesity to BP is more pronounced in women, including AA populations, as evidenced by a more closely associated $\mathrm{BP}$ increase per unit of BMI in women than in men [8, 45-47].
This is especially impactful in AA women who tend to have high rates of obesity [48]. Aldosterone levels are positively correlated with BMI $[49,50]$, a relationship that is stronger in women than in men [51]. Furthermore, experimental data indicates that obesity-associated BP increases and vascular dysfunction in female animal models is mediated by mineralocorticoid receptor activation [27-29]. Interestingly, in the current study, $\mathrm{AA} \mathrm{MH}+\mathrm{S}$ had similar BMI as compared to their female counterpart, but spironolactone treatment was not associated with a significant benefit in BP or BP control (Table 1). Additionally, white $\mathrm{FH}+\mathrm{S}$ had a statistically higher prevalence of diabetes and little to no benefit in BP control as compared to white FH, as opposed to the significant BP reductions reported in AA females with type 2 diabetes [26]. These data suggest that, in females, HTN is significantly ameliorated in our predominately obese AA HTN cohort by mineralocorticoid receptor blockade. This may due to sex differences in obesity-derived BP elevation mechanisms, a deduction that warrants further study.

\section{Perspectives}

Mineralocorticoid receptor antagonists, the primary derivatives being spironolactone and eplerenone, are used to treat hypokalemia, heart failure, acne, and polycystic ovary syndrome in addition to hypertensive indications. However, these drugs are generally reserved for patients with advanced-stage resistant HTN. These restrictions may have contributed to the small cohort size. In the current study, the average patient taking spironolactone was on $\sim 2$ antihypertensive medications and over the age of 60 . This postmenopausal age of AA females should have deleterious effects on BP control as compared to male counterparts [52], making the current findings stronger. Nevertheless, despite little data available, our data agrees with other evidence that mineralocorticoid receptor antagonism may be particularly beneficial in older AA females with HTN [26]. Further research is needed to identify these mechanisms that play a role in this population and on the patient-specific efficacy of this drug earlier in the progression of HTN.

\section{Limitations}

The results from the current study are exciting but are far from definitive. The need for follow-up studies and prospective clinical trials to confirm the race and sex-specific benefits of mineralocorticoid receptor antagonists is clear. One of the primary limitations of the current study is the low number of patients taking spironolactone. Future studies using a larger population, in addition to controlled clinical trials, are needed in to investigate the underlying mechanisms of mineralocorticoid receptor antagonists in AA. Another limitation of this study is that each patient's data was collected at a 
single time point. Thus, the patient's status before antihypertensive therapy is not known, and their physiological responses to spironolactone or the duration of spironolactone use is unknown. Spironolactone use during heart failure can skew the interpretation of BP, especially when ejection fraction is compromised, tending to decrease BP. AA with suspected heart failure (ejection fraction < 40) were removed from the analysis. However, white females on spironolactone had no echocardiography data to confirm the absence of heart failure as was done with the AA cohort. Even if this was a confounding factor in the white female cohort, this was not reflected in their $\mathrm{BP}$ or the proportion with uncontrolled HTN. Finally, direct comparisons between AA and white females were not performed due to insufficient power for comparing the spironolactone groups and due to possible confounding effects of geographic and socioeconomic factors.

\section{Acknowledgements}

None

\section{Funding}

This work was supported by grants from the American Heart Association (AHA 17POST33661071), the National Institute of General Medical Sciences (P20 GM104357), the National Science Foundation (NSF EPS 0903787) and the National Heart, Lung, and Blood Institute (P01 HL051971).

\section{Availability of data and materials}

The data that support the findings of this study are available from the Genetic Epidemiology Network of Arteriopathy but restrictions apply to the availability of these data and are not publicly available.

\section{Authors' contributions}

JC and JF contributed to the conception and design of the study and drafted the manuscript. JC and AM contributed to the analysis and interpretation of the data. KB was critical for the data acquisition. JC, JF, AM, $\mathrm{RH}$, and $\mathrm{KB}$ revised the manuscript. All authors read and approved the final manuscript.

\section{Ethics approval and consent to participate}

The Genetic Epidemiology Network of Arteriopathy was approved by the Institutional Review Board at both institutions (University of Mississippi Medical Center and Mayo Clinic), and all participants gave written informed consent.

\section{Consent for publication}

None.

\section{Competing interests}

The authors declare that they have no competing interests.

\section{Publisher's Note}

Springer Nature remains neutral with regard to jurisdictional claims in published maps and institutional affiliations.

\section{Author details}

${ }^{1}$ Department of Physiology and Biophysics, Center for Computational Medicine, University of Mississippi Medical Center, 2500 North State Street, Jackson, MS 39216-4505, USA. ${ }^{2}$ Department of Data Sciences, John D. Bower School of Population Health, University of Mississippi Medical Center, Jackson, MS 39216-4505, USA. ${ }^{3}$ Department of Medicine, University of Mississippi Medical Center, Jackson, MS 39216-4505, USA. "Vascular Biology Center, Medical College of Georgia, Augusta University, Augusta, GA 30912-5563, USA.
Received: 21 December 2018 Accepted: 16 April 2019

Published online: 09 May 2019

\section{References}

1. Zhang Y, Moran AE. Trends in the prevalence, awareness, treatment, and control of hypertension among young adults in the United States, 1999 to 2014. Hypertension. 2017;70(4):736-42.

2. Dolan $\mathrm{E}$, et al. Superiority of ambulatory over clinic blood pressure measurement in predicting mortality: the Dublin outcome study. Hypertension. 2005;46(1):156-61.

3. Palatini $P$, et al. Added predictive value of night-time blood pressure variability for cardiovascular events and mortality: the Ambulatory Blood Pressure-International Study. Hypertension. 2014;64(3):487-93.

4. James PA, et al. 2014 evidence-based guideline for the management of high blood pressure in adults: report from the panel members appointed to the Eighth Joint National Committee (JNC 8). JAMA. 2014;311(5):507-20.

5. Reisin $\mathrm{E}$, et al. Lisinopril versus hydrochlorothiazide in obese hypertensive patients: a multicenter placebo-controlled trial. Treatment in Obese Patients With Hypertension (TROPHY) Study Group. Hypertension. 1997;30(1 Pt 1): $140-5$.

6. Wofford MR, et al. Antihypertensive effect of alpha- and beta-adrenergic blockade in obese and lean hypertensive subjects. Am J Hypertens. 2001; 14(7 Pt 1):694-8.

7. Yoon SS, et al. Trends in blood pressure among adults with hypertension: United States, 2003 to 2012. Hypertension. 2015;65(1):54-61.

8. Sampson UK, et al. Factors associated with the prevalence of hypertension in the southeastern United States: insights from 69,211 blacks and whites in the Southern Community Cohort Study. Circ Cardiovasc Qual Outcomes. 2014;7(1):33-54.

9. Lloyd-Jones D, et al. Heart disease and stroke statistics--2009 update: a report from the American Heart Association Statistics Committee and Stroke Statistics Subcommittee. Circulation. 2009;119(3):e21-181.

10. Mensah GA, et al. State of disparities in cardiovascular health in the United States. Circulation. 2005;111(10):1233-41.

11. Flack JM, et al. Management of high blood pressure in blacks: an update of the international society on hypertension in blacks consensus statement. Hypertension. 2010;56(5):780-800.

12. Giles $T$, et al. Ethnic/racial variations in blood pressure awareness, treatment, and control. J Clin Hypertens (Greenwich). 2007;9(5):345-54

13. He FJ, et al. Importance of the renin system in determining blood pressure fall with salt restriction in black and white hypertensives. Hypertension. 1998;32(5):820-4.

14. He J, et al. The renin-angiotensin system and blood pressure: differences between blacks and whites. Am J Hypertens. 1999;12(6):555-62.

15. Mc Causland FR, et al. Race, plasma renin activity, and morning blood pressure surge--results from the Dietary Approaches to Stop Hypertension trial. Am J Hypertens. 2014;27(4):530-6.

16. Price DA, Fisher ND. The renin-angiotensin system in blacks: active, passive, or what? Curr Hypertens Rep. 2003;5(3):225-30.

17. Huan $Y$, et al. Aldosterone and aldosterone: renin ratio associations with insulin resistance and blood pressure in African Americans. J Am Soc Hypertens. 2012;6(1):56-65.

18. Scott $L$, et al. Aldosterone-to-renin ratio and the relationship between urinary salt excretion and blood pressure in a community of African ancestry. Am J Hypertens. 2011;24(8):951-7.

19. Satoh $\mathrm{M}$, et al. Association of aldosterone-to-renin ratio with hypertension differs by sodium intake: the Ohasama study. Am J Hypertens. 2015;28(2): 208-15

20. Satoh $\mathrm{M}$, et al. Role of angiotensinogen and relative aldosterone excess in salt-sensitive hypertension. Hypertension. 2012;59(6):e57 author reply e58.

21. Wright JT Jr, et al. Determinants of salt sensitivity in black and white normotensive and hypertensive women. Hypertension. 2003;42(6):1087-92.

22. Kotchen TA, et al. Aldosterone and alterations of hypertension-related vascular function in African Americans. Am J Hypertens. 2009;22(3):319-24.

23. Pitt $B$, et al. The effect of spironolactone on morbidity and mortality in patients with severe heart failure. Randomized Aldactone Evaluation Study Investigators. N Engl J Med. 1999;341(10):709-17.

24. Rales Investigators. Effectiveness of spironolactone added to an angiotensinconverting enzyme inhibitor and a loop diuretic for severe chronic congestive heart failure (the Randomized Aldactone Evaluation Study [RALES]). Am J Cardiol. 1996;78(8):902-7. 
25. Joseph JJ, et al. Aldosterone, renin, and diabetes mellitus in African Americans: the Jackson heart study. J Clin Endocrinol Metab. 2016;101(4): 1770-8

26. Khosla N, Kalaitzidis R, Bakris GL. Predictors of hyperkalemia risk following hypertension control with aldosterone blockade. Am J Nephrol. 2009;30(5): 418-24.

27. Bostick B, et al. Mineralocorticoid receptor blockade prevents Western dietinduced diastolic dysfunction in female mice. Am J Physiol Heart Circ Physiol. 2015;308(9):H1126-35.

28. DeMarco VG, et al. Low-dose mineralocorticoid receptor blockade prevents Western diet-induced arterial stiffening in female mice. Hypertension. 2015; 66(1):99-107.

29. Huby AC, Otvos L Jr, Belin de Chantemele EJ. Leptin induces hypertension and endothelial dysfunction via aldosterone-dependent mechanisms in obese female mice. Hypertension. 2016;67(5):1020-8.

30. Investigators, F. Multi-center genetic study of hypertension: the family blood pressure program (FBPP). Hypertension. 2002;39(1):3-9.

31. Williams RR, et al. Usefulness of cardiovascular family history data for population-based preventive medicine and medical research (the health family tree study and the NHLBI family heart study). Am J Cardiol. 2001; 87(2):129-35.

32. Alvarez-Alvarez $B$, et al. Management of resistant arterial hypertension: role of spironolactone versus double blockade of the renin-angiotensinaldosterone system. J Hypertens. 2010;28(11):2329-35.

33. Djoumessi RN, et al. Effect of low-dose spironolactone on resistant hypertension in type 2 diabetes mellitus: a randomized controlled trial in a sub-Saharan African population. BMC Res Notes. 2016;9:187.

34. Nishizaka MK, Zaman MA, Calhoun DA. Efficacy of low-dose spironolactone in subjects with resistant hypertension. Am J Hypertens. 2003;16(11 Pt 1): 925-30.

35. Ghazi $L$, et al. Urinary sodium excretion predicts blood pressure response to spironolactone in patients with resistant hypertension independent of aldosterone status. J Hypertens. 2016;34(5):1005-10.

36. Williams B, et al. Spironolactone versus placebo, bisoprolol, and doxazosin to determine the optimal treatment for drug-resistant hypertension (PATHWAY-2): a randomised, double-blind, crossover trial. Lancet. 2015; 386(10008):2059-68.

37. Chapman $\mathrm{N}$, et al. Effect of spironolactone on blood pressure in subjects with resistant hypertension. Hypertension. 2007:49(4):839-45.

38. Dudenbostel T, Calhoun DA. Use of aldosterone antagonists for treatment of uncontrolled resistant hypertension. Am J Hypertens. 2017;30(2):103-9.

39. Calhoun DA, et al. Resistant hypertension: diagnosis, evaluation, and treatment: a scientific statement from the American Heart Association Professional Education Committee of the Council for High Blood Pressure Research. Circulation. 2008;117(25):e510-26.

40. Egan BM, et al. Uncontrolled and apparent treatment resistant hypertension in the United States, 1988 to 2008. Circulation. 2011;124(9):1046-58.

41. Henry SL, et al. Developmental origins of obesity-related hypertension. Clin Exp Pharmacol Physiol. 2012;39(9):799-806.

42. Kannel WB, Zhang T, Garrison RJ. Is obesity-related hypertension less of a cardiovascular risk? The Framingham Study. Am Heart J. 1990;120(5):1195-201.

43. Lloyd-Jones DM, et al. Differential control of systolic and diastolic blood pressure: factors associated with lack of blood pressure control in the community. Hypertension. 2000;36(4):594-9.

44. Faulkner JL, Belin de Chantemele EJ. Sex differences in mechanisms of hypertension associated with obesity. Hypertension. 2018;71(1):15-21.

45. de Simone $\mathrm{G}$, et al. Risk factors for arterial hypertension in adults with initial optimal blood pressure: the strong heart study. Hypertension. 2006;47(2): $162-7$.

46. Fujita M, Hata A. Sex and age differences in the effect of obesity on incidence of hypertension in the Japanese population: a large historical cohort study. J Am Soc Hypertens. 2014;8(1):64-70.

47. Wilsgaard T, Schirmer H, Arnesen E. Impact of body weight on blood pressure with a focus on sex differences: the Tromso Study, 1986-1995. Arch Intern Med. 2000;160(18):2847-53.

48. Wang Y, Beydoun MA. The obesity epidemic in the United States-gender, age, socioeconomic, racial/ethnic, and geographic characteristics: a systematic review and meta-regression analysis. Epidemiol Rev. 2007;29:6-28.

49. Rocchini AP, et al. Role for aldosterone in blood pressure regulation of obese adolescents. Am J Cardiol. 1986;57(8):613-8.
50. Rossi GP, et al. Body mass index predicts plasma aldosterone concentrations in overweight-obese primary hypertensive patients. J Clin Endocrinol Metab. 2008;93(7):2566-71.

51. Goodfriend $\mathrm{TL}$, et al. Visceral obesity and insulin resistance are associated with plasma aldosterone levels in women. Obes Res. 1999;7(4):355-62.

52. Lima R, Wofford M, Reckelhoff JF. Hypertension in postmenopausal women. Curr Hypertens Rep. 2012;14(3):254-60.

\section{Ready to submit your research? Choose BMC and benefit from:}

- fast, convenient online submission

- thorough peer review by experienced researchers in your field

- rapid publication on acceptance

- support for research data, including large and complex data types

- gold Open Access which fosters wider collaboration and increased citations

- maximum visibility for your research: over $100 \mathrm{M}$ website views per year

At BMC, research is always in progress.

Learn more biomedcentral.com/submissions 